\title{
A outra racionalidade da economia solidária. Conclusões do primeiro Mapeamento Nacional no Brasil
}

The other rationale of the solidary economy. Conclusions of the first National Survey of Brazil

L'autre rationalité de l'économie solidaire. Conclusions du premier Levé National au Brésil

\section{Luiz Inácio Gaiger}

\section{OpenEdition}

\section{Journals}

Edição electrónica

URL: http://journals.openedition.org/rccs/725

DOI: $10.4000 /$ rccs.725

ISSN: 2182-7435

\section{Editora}

Centro de Estudos Sociais da Universidade de Coimbra

Edição impressa

Data de publição: 1 Dezembro 2007

Paginação: 57-77

ISSN: 0254-1106

\section{Refêrencia eletrónica}

Luiz Inácio Gaiger, «A outra racionalidade da economia solidária. Conclusões do primeiro Mapeamento Nacional no Brasil », Revista Crítica de Ciências Sociais [Online], 79 | 2007, colocado online no dia 01 outubro 2012, criado a 19 abril 2019. URL : http://journals.openedition.org/rccs/725 ; DOI : $10.4000 /$ rccs. 725 


\section{LUIZ INÁCIO GAIGER}

\section{A outra racionalidade da economia solidária. Conclusões do primeiro Mapeamento Nacional no Brasil'}

O artigo examina os resultados empíricos do primeiro levantamento nacional sobre a economia solidária realizado no Brasil, que coletou dados sobre quase $22 \mathrm{mil}$ experiências. Seu objetivo é verificar em que medida esses empreendimentos, por se tratar de organizações fundadas na livre associação de trabalhadores, na cooperação produtiva e em princípios de autogestão, adotam uma racionalidade distinta e contraposta sob certos aspectos à lógica econômica intrínseca à acumulação contínua de capital. A análise centra-se nas relações entre indicadores de solidarismo interno e externo dos empreendimentos e indicadores de eficiência e viabilidade econômica. Como resultado, embora debilidades e limites sejam identificados nessas experiências, é perceptível sua tendência geral a realizarem os seus fins, de preservação da vida em condições dignas, através da participação democrática e da reciprocidade.

Desde meados dos anos 1980, assiste-se no Brasil e em outros países ao florescimento e ao gradativo fortalecimento de iniciativas de trabalhadores no campo econômico, fundadas no associativismo e na cooperação. Embora menosprezadas até alguns anos atrás, essas experiências converteram-se em alternativas duradouras para um número crescente de trabalhadores. Aos poucos, de suas diferentes vertentes originais, estabeleceram campos de diálogo e de criação de uma identidade comum, expressa em inúmeros movimentos organizados, com destacada atuação nas edições do Fórum Social Mundial. A economia solidária estabeleceu-se ao Sul e ao Norte, como ator social, como item da agenda política e como tema de estudos (Cattani, 2004), despertando a atenção para a importância de ser conhecida e compreendida de modo abrangente e fundamentado.

\footnotetext{
${ }^{1}$ Trabalho desenvolvido com apoio do CNPq, no âmbito do Programa de Pós-Graduação em Ciências Sociais da Universidade do Vale do Rio dos Sinos. Agradeço a assistência estatística da Prof. ${ }^{a}$ Patrícia Kuyven.
} 
Um levantamento amplo sobre a economia solidária acaba de realizar-se no Brasil. Conhecido como primeiro Mapeamento Nacional, foi idealizado pelo Fórum Brasileiro de Economia Solidária e pelo Governo Federal, com o apoio de universidades, instituições de pesquisa e ONGs. Em 2006, o término da etapa principal de coleta de informações resultou em uma base de dados sobre 15 mil Empreendimentos de Economia Solidária (EES), envolvendo uma população estimada de 1,2 milhão de participantes, em todos os Estados do país e em $41 \%$ dos municípios. Em fins de 2007, uma pesquisa de campo complementar propiciou a inserção de mais sete mil empreendimentos na base de dados.

Esse artigo explora os resultados já consolidados da base gerada em 2006, tendo em vista uma questão central dos estudos acadêmicos e do debate público: a caracterização dos empreendimentos de economia solidária como portadores de uma racionalidade específica, relativa ao modo como ativam os seus recursos produtivos, humanos e materiais. Isto, por se tratar de sociedades de pessoas - não de capitais - e possuírem características singulares, tais como a indivisão entre proprietários e trabalhadores, a gestão coletiva e o engajamento em movimentos e redes, alinhadas hoje em uma mobilização internacional de construção da identidade política da economia solidária (Mendel, 2003).

As diferenças estruturais entre as empresas capitalistas e as empresas cooperativas e autogestionárias são reconhecidas de longa data pela literatura (Jones, 1978; Defourny, 1988; Namorado, 2005). A presença de uma racionalidade distinta da capitalista, orientada à preservação da vida, já foi evidenciada em estudos comparativos sobre a economia solidária (Santos 2002; Novaes, 2005; Gaiger, 2006, 2007) e sustenta as expectativas quanto ao fato de ela materializar princípios de outra economia, portadora de um projeto substitutivo dos atuais modelos de desenvolvimento (Cattani, 2004). O Mapeamento oportuniza uma volta privilegiada ao tema, ao oferecer uma base empírica ineditamente representativa das experiências atuais no Brasil. Este artigo a examina com um duplo objetivo: primeiramente, o de aplicar técnicas quantitativas de análise para identificar as características predominantes e os elementos que estruturam os EES, de modo a verificar em que medida sustentam a hipótese de uma racionalidade específica, como tendência geral - e por isso, fundamental - da economia solidária. Em segundo lugar, tenciona-se exemplificar como essa base de dados pode ser utilmente explorada e sugerir prismas para análises tópicas mais aprofundadas, mediante cotejo com os resultados de pesquisas qualitativas, bem mais usuais nesse campo de estudos. 
O artigo inicia com algumas considerações sobre o conceito de racionalidade, a fim de elucidar preliminarmente seu conteúdo e a pertinência de sua abordagem. A seguir, esclarecimentos sobre as características da base de dados do Mapeamento servem para indicar sua validade e precisar o método adotado para a análise desenvolvida nas seções subseqüentes do texto, a partir de três questões sucessivas: a) antes de tudo, os EES apresentam características consistentes que permitam classificá-los como agentes econômicos moldados pelo associativismo e pela cooperação produtiva? b) em segundo lugar, existem incidências positivas e orgânicas entre a dimensão solidária e a dimensão empreendedora dos EES, capazes de instaurar uma lógica singular e circular, a um só tempo social e econômica? c) por fim, que relevância essa lógica possui para a estrutura dos EES e de que modo tende a acentuar-se com o desenvolvimento da práxis econômica solidária? As respostas a essas questões, a nosso ver, permitirão avaliar em que medida os EES caracterizam-se como experiências dotadas de uma racionalidade singular, na qual a reciprocidade constitui um esteio primordial da ação econômica.

Ao centrar-se na totalidade dos empreendimentos mapeados, a análise deixa de fazer referências a exemplos concretos e de trazer diretamente à baila a notória diversidade da economia solidária no Brasil, quanto aos setores econômicos, às categorias sociais envolvidas e às formas de organização. Essa diversidade, relevante, seria de consideração indispensável em análises subseqüentes, sugeridas ao final do texto.

\section{Economias e racionalidades}

Uma compreensão estreita e discriminatória da economia domina o nosso senso comum, graças a três reducionismos introduzidos desde o séc. XIX pela economia neoclássica e seus axiomas utilitaristas: a) a redução de toda economia à economia de mercado; b) a redução de todo mercado ao mercado auto-regulado; c) a redução de toda empresa econômica à empresa capitalista (Laville, 2004). Nessa ótica, quem não pertence a esses setores é visto como sinal de atraso ou ineficiência e relegado a um papel secundário; para os pobres, restaria uma espécie de economia de sobrevivência com funções sociais, de freio à marginalização, mais do que propriamente econômicas.

Ora, ao longo da história uma ampla parcela das atividades econômicas, geradora de riqueza e de bem-estar, esteve à margem ou em relação indireta com o sistema produtivo e o mercado capitalista, valendo-se antes dos seus recursos autóctones e de circuitos locais, no "andar térreo da civilização" segundo a conhecida formulação de Fernand Braudel. A sobrevivência e a prosperidade de importantes segmentos da população estiveram garantidas 
por práticas e estruturas de produção e de troca orientadas por lógicas internas de outro tipo (Coraggio, 1999; Santos, 2002). No Brasil, parte expressiva da riqueza nacional provém dessas atividades, como é patente no caso da pequena produção agrícola, cujo desempenho nos anos recentes evidencia uma capacidade de modernizar-se e tornar-se mais produtiva, sem perder o seu caráter familiar. Tampouco os segmentos mais pobres estão desprovidos de iniciativas e de estratégias econômicas de eficiência apreciável (Abramovay, 2004).

Outras economias, produtivas e orientadas ao intercâmbio de bens, existiam antes da disseminação das relações capitalistas. Desse ângulo, o capitalismo é que representou a introdução de outra economia, gradativamente sobreposta a formas econômicas pré-existentes, taxadas de pré-capitalistas como se fossem mero preâmbulo da economia dita superior do capital. Diante do advento das relações capitalistas, os trabalhadores reagiram de várias formas, combatendo a exploração no interior da empresa capitalista, criando alternativas de caráter associativo (Singer, 1999) ou defendendo seus sistemas de vida próprios, seu patrimônio produtivo e seus saberes, contra a ameaça de espoliação e de subordinação do capital.

A depender dos critérios de análise, considerar a forma capitalista mais moderna, no sentido de superior, perde o seu sentido. Basta que se abra mão do axioma do crescimento e da máxima rentabilidade, ou do próprio paradigma do desenvolvimento, para que as coisas mudem de figura. A alternativa de agir coletivamente manteve-se e renovou-se entre os trabalhadores, gerando o cooperativismo operário no séc. XIX, o associativismo e a economia social na passagem ao séc. XX, a economia solidária na entrada do séc. XXI, por uma razão fundamental: brindar segurança, reconhecimento e vida significativa à imensa maioria de pessoas que vivem primordialmente da sua capacidade de trabalho. Tais experiências, em alguns casos, produziram relações sociais antagônicas ao capitalismo; em muitos outros casos, preservaram relações sociais não capitalistas, atenuando assim a sujeição dos trabalhadores à economia dominante e conjurando o exclusivismo das relações assalariadas de subordinação e expropriação, a eles reservadas como via de integração social.

Para esses indivíduos, não fossem as circunstâncias instituídas pelo capital, pouco sentido haveria em lidar com uma economia exógena e contraposta ao trabalho, muito menos partilhar o senso comum sobre a sua superioridade. Desde as suas origens modernas, coube à reciprocidade cumprir um papel vital de alargamento da experiência humana de reprodução da vida, ao contrapor-se às determinações e às limitações impostas pela racionalidade estrita do capital. Mantiveram-se assim vigentes outros princípios e outras lógicas de organização do trabalho, de criação de bens e de cir- 
culação da riqueza, ao lado da economia de mercado capitalista, configurando uma economia plural, nos termos da Nova Sociologia Econômica (Lévesque et al., 2001).

O cenário atual apresenta desafios consideráveis à economia solidária, pois o leque de carências e de aspirações humanas amplia-se, frustrando-se ao mesmo tempo a esperança de serem atendidas através da lógica de produção incessante de mercadorias. Esta lógica introduz requisitos cada vez mais exigentes de competências, inovação e desempenho competitivo, para a viabilidade das empresas capitalista e das formas alternativas de produção. O valor da economia solidária, para os trabalhadores que nela apostam, depende então de sua capacidade de responder aos requerimentos de eficiência - não somente econômica, mas sistêmica ${ }^{2}$ - e promover simultaneamente experiências significativas de trabalho, assentes na eqüidade e em vínculos sociais não utilitários.

Essa relação orgânica entre a dimensão solidária, de autogestão e de cooperação no trabalho, e a dimensão empreendedora, de organização e gestão dos fatores produtivos com vistas à realização das metas dos empreendimentos, é o que constitui a sua racionalidade específica (Gaiger, 2004b). O termo significa que as práticas em tela são concomitantes e entrelaçam-se, estabelecendo uma dinâmica objetiva para a ação dos indivíduos, uma pressão estrutural para que procedam de uma dada maneira, precisamente porque, no contexto assim criado, tal conduta assevera-se mais lógica. $\mathrm{O}$ êxito dos empreendimentos fica então vinculado a fatores cujo efeito positivo decorre do caráter socialmente cooperativo por eles incorporado. Institui-se uma comunidade de trabalho, que passa a co-determinar a racionalidade econômica (Gaiger, 2004b; 2006). . De forma sistemática, exploram-se os ativos potenciais propiciados pela união dos trabalhadores, valendo-se do fato de que

um elemento comunitário, de ação e gestão conjunta, cooperativa e solidária, apresente no interior dessas unidades econômicas efeitos tangíveis e concretos sobre o resultado da operação econômica. Efeitos concretos e específicos nos quais se possa

\footnotetext{
${ }^{2}$ A eficiência sistêmica compreende a capacidade de promover a qualidade de vida das pessoas e propiciar bem-estar duradouro para a sociedade. Abrange os benefícios sociais, não meramente monetários ou econômicos, para os membros e o entorno das organizações em questão, a garantia de longevidade para as mesmas e a criação de externalidades positivas sobre o ambiente natural (Gaiger, 2004a).

${ }^{3}$ Esse agenciamento dos recursos produtivos dos trabalhadores diferencia-se das modalidades predominantes da economia popular, cujos vínculos de reciprocidade nem sempre refletem princípios igualitários e democráticos e na qual estão em jogo necessidades imediatas de sobrevivência ou, quando muito, a preservação de meios de subsistência, num quadro inalterável de pobreza e dependência.
} 
discernir uma particular produtividade dada pela presença e crescimento do referido elemento comunitário, análoga à produtividade que distingue e pela qual se reconhecem os demais fatores econômicos. (Razeto, 1993: 40-1)

Ao darem-se as mãos, os trabalhadores fortalecem seu poder de ação e aumentam suas chances de resolverem problemas e realizarem projetos. Sem essa expectativa, a economia solidária seria inexplicável. Mas sem lograr esse objetivo razoavelmente, ela seria apenas uma idealização de dias contados. Portanto, desse desafio depende a resposta a muitas outras questões, a respeito da força de expansão e do significado histórica da economia solidária. Por isso, as explorações dos dados do Mapeamento devem indagar se os empreendimentos de economia solidária retiram da participação e da cooperação a sua força econômica, instaurando uma relação de simbiose entre solidarismo e eficiência. É plausível falar de outra economia, de práticas inspiradas em valores e induzidas simultaneamente por uma lógica objetiva singular dos empreendimentos?

\section{O Mapeamento e a validação dos dados}

O crescimento da economia solidária no Brasil é um fato notável nas duas últimas décadas, relatado em estudos panorâmicos (França Filho et al., 2006; Gaiger, 2007) e confirmado pelo Mapeamento: $87 \%$ dos EES registrados tiveram início posterior a 1990,35\% após 2002. Ao mesmo tempo, a articulação gradativa dos empreendimentos e das organizações de apoio resultou em estruturas representativas da economia solidária, culminando com a criação do Fórum Brasileiro de Economia Solidária, em 2003. ${ }^{4}$ A economia solidária converteu-se em tema de estudos acadêmicos, alimentando as perspectivas de um pensamento crítico orientado desde o Sul (Cattani, 2004; Coraggio, 2007), e passou a constar da agenda de governos municipais e estaduais. Com a vitória de Lula, em 2003, instalou-se a Secretaria Nacional de Economia Solidária, incumbida, em conjunto com o Fórum, de idealizar e realizar o Mapeamento. Uma meta louvável do Mapeamento foi atingir, o mais possível, as experiências solidárias desconhecidas, não integradas aos circuitos de reconhecimento da economia solidária, para dar voz a seus protagonistas. A tarefa envolveu cerca de 230 entidades e mais de 600 técnicos e entrevistadores.

\footnotetext{
${ }^{4}$ O Fórum Brasileiro foi criado na III Plenária Nacional da Economia Solidária, com mais de 800 representantes, delegados das 18 plenárias estaduais. Seu papel consiste em articular e mobilizar as bases sociais da economia solidária pelo país, a partir de sua Carta de Princípios e de sua Plataforma de Lutas, e fazer a interlocução com o governo, em especial a Secretaria Nacional da Economia Solidária.
} 
Por sua abrangência, o Mapeamento viabiliza uma mudança de escala nos trabalhos acadêmicos e nos debates sobre a economia solidária. Até então, a inexistência de dados objetivos e abrangentes sobre as experiências de economia solidária no país limitou os estudos a uma abordagem qualitativa, valiosa para o exame dos traços particulares dessas iniciativas, mas insuficiente para identificar suas tendências predominantes e seu impacto sobre as condições de vida dos trabalhadores. Os dados do Mapeamento, integrados ao Sistema Nacional de Informações da Economia Solidária SIES, oferecem uma visão ampla do perfil econômico, social e político da economia solidária. ${ }^{5}$ As perguntas formuladas, sobre os membros dos EES e as circunstâncias de sua criação, suas atividades econômicas, sua organização e gestão, seus vínculos e sua atuação social, produziram uma massa de informações passível de análise sob diversos ângulos, quanto à gênese e aos padrões de desenvolvimento dos EES, além de fundamental para a seleção judiciosa de casos a serem estudados qualitativamente. ${ }^{6}$

Tratar os dados do SIES sob o prisma da racionalidade intrínseca aos empreendimentos requer um dispositivo analítico apropriado, de modo a abarcar o maior número de informações relacionadas ao tema e dar margem ao contraditório, contido nas informações colhidas ou na sua (aparente) inconsistência. O método adotado com esse propósito foi uma extensão dos procedimentos empregados numa etapa preliminar, de crítica e de validação da base de dados. Essas tarefas prévias eram indispensáveis, pois as características do Mapeamento o diferenciam de uma pesquisa convencional e o expuseram a distorções, da identificação do seu universo até o registro e a transmissão dos dados. ${ }^{7}$ Os dados sofreram então um processo

\footnotetext{
${ }^{5}$ Os dados finais do Mapeamento ainda não estavam disponíveis quando da redação desse artigo, que se vale da base consolidada de 2006. Para uma caracterização muito breve: $54,5 \%$ dos EES são associações, $32,7 \%$ funcionam como grupos informais e $10,7 \%$ são cooperativas. As atividades coletivas mais comuns são a produção (61\%), a comercialização $(57 \%)$ e o uso de equipamentos produtivos (48\%). A fisionomia rural da economia solidária é visível, uma vez que $64 \%$ dos EES dedicam-se à agricultura, pecuária, pesca ou extrativismo. Seguem-se os setores de prestação de serviços (14\%), alimentos (produção, beneficiamento e serviços - $13 \%$ ), têxtil, confeções e calçados (12\%), artesanato $(9 \%)$, indústria de transformação $(6 \%)$, coleta e reciclagem $(4 \%)$ e finanças $(2 \%)$. O retrato da economia solidária revelado pelo Mapeamento teve considerável difusão, através do Atlas da Economia Solidária, publicado em abril de 2006 e das opções de acesso ao SIES (www.sies.mte.gov.br). ${ }^{6} \mathrm{O}$ que contribuiria para superar a abordagem corrente, empirista e intuitiva, dos métodos de estudo de caso, que se contenta em escolher o que subjetivamente parece mais relevante ou está mais à mão do pesquisador.

${ }^{7}$ A falta de uma relação preliminar dos EES existentes no território nacional, devido à notória insuficiência de informações prévias, representou um obstáculo considerável. A listagem foi então elaborada a partir de cadastros parciais e de informações diretas. O Mapeamento equivale tecnicamente a um levantamento amplo de informações, não a um censo ou a uma pesquisa amostral. O tratamento dos dados foi coordenado pelo autor desse artigo e por Hérton Araújo, do Instituto de Pesquisas Econômicas Aplicadas.
} 
de retificação, mediante testes de consistência que resultaram na criação de novas variáveis e em reclassificações de respostas. Dentro de patamares razoáveis de confiabilidade, a base de dados do SIES foi validada.

Mas além de verificar o atendimento a requisitos técnicos, a crítica dos dados serviu para mensurar o grau de correspondência entre as experiências mapeadas e o conceito teórico de empreendimentos de economia solidária. Com isso, aportou uma conclusão preliminar decisiva para os objetivos desse artigo.

Para serem mapeados, os EES deviam satisfazer seis requisitos: a) constituírem organizações suprafamiliares permanentes; b) sob propriedade ou controle dos sócios-trabalhadores; c) com emprego ocasional e minoritário de trabalhadores não-associados; d) com gestão coletiva das suas atividades e da alocação dos resultados; e) com registro legal ou informais; f) de natureza econômica, direcionada à produção, comercialização, serviços, crédito ou consumo. Uma bateria de testes de consistência buscou identificar os empreendimentos registrados em desacordo com esses parâmetros. ${ }^{8}$ As iniciativas situadas fora do escopo previsto ou não seriam organizações econômicas permanentes e suprafamiliares ou, mesmo o sendo, não funcionariam de modo minimamente autogestionário ou com vistas à sua viabilidade econômica. Poderiam representar formas habituais ou momentâneas de solidariedade, praticadas por indivíduos e por famílias detentores dos seus negócios, mas não organizações instituídas por meio de um ato associativo deliberado entre indivíduos, ou seja, de empreendimentos solidários, cujo alastramento confere a novidade e a importância da economia solidária.

Ante nossas categorias de análise, as organizações incluídas indevidamente no SIES faltariam com os requisitos mínimos de uma racionalidade ao mesmo tempo empreendedora e solidária. Essas dimensões significam que a união e a inteligência coletiva dos trabalhadores são mobilizadas como recursos fundamentais para que os EES lidem com a realidade contingente e logrem sua sobrevivência, gerando benefícios à comunidade de pessoas neles implicadas. Por certo, tal lógica não se destina a produzir novos empresários dispostos a correr os riscos inerentes aos jogos da acumulação do capital, mas a prover e repor os meios de vida. Metas improváveis na ausên-

\footnotetext{
${ }_{8}^{8}$ A inexistência de uma listagem consolidada e o perfil heterogêneo dos entrevistadores de campo justificavam esse cuidado, sendo de esperar, por exemplo, a inclusão indevida de organizações sociais ou filantrópicas sem atuação econômica, ou de empreendimentos não conduzidos efetivamente pelos sócios-trabalhadores. A base conceitual e a metodologia do Mapeamento constam do Atlas da Economia Solidária no Brasil e de outros documentos de referência disponíveis em www.sies.mte.gov.br.
} 
cia de um projeto comum forjado pela experiência do trabalho, a partir do qual se exerce a criatividade, cultivam-se vínculos não-utilitários e realiza-se o aprendizado (Gaiger, 2004b).

Quanto mais freqüentes os casos de inobservância desses requisitos pelos EES, mais distantes estaríamos da hipótese de existência de uma lógica baseada na conjunção daquelas duas dimensões. Sendo tais casos predominantes entre as 15 mil experiências registradas no SIES, o próprio conceito de economia solidária estaria sujeito a cair por terra. ${ }^{9} \mathrm{O}$ primeiro teste consistiu em examinar os EES cujas declarações não condiziam com aqueles requerimentos. Estando esses casos associados entre si e a situações não aleatórias, revelariam debilidades sistêmicas da economia solidária. Se, ao contrário, essas hipóteses negativas fossem rejeitadas, os EES teriam passado no teste. Portanto, uma contraprova, no sentido de expor à falsificação as inferências feitas a partir dos dados favoráveis à economia solidária.

Dez hipóteses foram examinadas, concluindo-se que os EES em geral apresentam práticas solidárias e empreendedoras acima de um patamar mínimo e atendem ao marco de referência do SIES. Certas fragilidades apareceram, como a falta de recursos e de infra-estrutura, fatores de dependência das iniciativas de economia solidária, ou o baixo grau de envolvimento dos associados na vida cotidiana de alguns empreendimentos, acarretando riscos de cisão entre o corpo diretivo e a base social. Por outro lado, sobressaíram-se aspectos positivos, como a existência de mecanismos democráticos e a ampla predominância dos sócios na direção e na execução das atividades, além da participação freqüente em mobilizações sociais.

Para uma avaliação mais abrangente e conclusiva, foram construídos dois coeficientes, de baixo empreendedorismo e de baixo solidarismo, formados a partir de indicadores de práticas ou situações negativas, semelhantes àquelas examinadas nas hipóteses anteriores. O objetivo era aferir se essas práticas ou situações são fatos isolados ou vinculados entre si. Uma espécie de malha fina: quanto maior a sua pontuação, menos empreendedores ou solidários os EES seriam. Quanto mais freqüentes as pontuações elevadas, mais comprometida ficaria a natureza alternativa dos EES e deveríamos admitir que a economia solidária no Brasil esteja longe de conter elementos efetivos de outra lógica social e econômica.

O desempenho global dos EES mostrou-se satisfatório, no que tange a não possuírem propriedades ou exercerem práticas cabalmente indicadoras da ausência de empreendedorismo ou de solidarismo: 93,7\% deles incidem

\footnotetext{
${ }_{9}$ Exceto se ficasse demonstrado que os autênticos empreendimentos não foram mapeados, algo sem qualquer evidência empírica.
} 
no máximo em 6 indicadores, dos 18 utilizados, e apenas $0,5 \%$ incidem em 9 indicadores ou mais. Existem EES muito frágeis ou em situações contraditórias com o conceito de economia solidária. Porém, como todas as frações referentes aos EES com elevado coeficiente de baixo empreendedorismo ou de baixo solidarismo são inferiores a 1,5\%, pode-se dizer que o SIES, salvo tais exceções, registra experiências classificáveis como de economia solidária. Apesar da aparente redundância, conclui-se que o conceito de economia solidária, no sentido de um conjunto de práticas guiadas por uma racionalidade que concilia solidariedade social e viabilidade econômica, encontra um suporte expressivo na realidade empírica captada pelo Mapeamento.

\section{Altos e baixos do desempenho solidário e empreendedor}

Esse resultado ainda é parcial. Diante da primeira questão indicada na Introdução, sobre os traços singulares e consistentes dos EES, é necessário averiguar se os mesmos ficam rentes aos níveis mínimos de empreendedorismo e solidarismo ou os superam em graus razoáveis, com bons indicadores positivos. Seu desempenho será mais convincente se apresentarem quocientes pronunciados em indicadores exigentes, apropriados a uma concepção avançada de economia solidária.

Para essa avaliação, utilizou-se um dispositivo metodológico tecnicamente similar ao anterior, mas de conteúdo oposto: os EES foram analisados segundo sua pontuação em coeficientes de alto empreendedorismo e de alto solidarismo, compostos cada um deles por nove indicadores. Como o adjetivo alto deixa a entender, pontuar em cada indicador implica responder a um conjunto de requisitos acima das condições esperadas da maioria dos EES; pontuar em vários indicadores exige desenvoltura em muitas frentes, ficando atendido o objetivo principal da análise. ${ }^{10}$

- Coeficiente de alto empreendedorismo:

1. Recursos produtivos a montante de propriedade do empreendimento

2. Sede, equipamentos e espaço principais de comercialização próprios

3. Comercialização principal no mercado estadual, nacional ou internacional

4. Visão estratégica e ausência de dificuldades de comercialização

5. Capacidade de captação de crédito para investimento

\footnotetext{
${ }^{10}$ Cada indicador relaciona-se a um conjunto de questões afins, consideradas simultaneamente ou alternativamente. Como os indicadores de alto desempenho não recaem nas mesmas variáveis utilizadas pelos indicadores de baixo desempenho, evita-se dividir tautologicamente os empreendimentos em dois pólos dicotômicos, conforme tenham respondido sim ou não às questões. Por outro lado, essa técnica nem sempre permite escolher os melhores indicadores do ponto de vista conceitual, pois é necessário ater-se às informações disponíveis na base de dados.
} 
6. Geração de sobra líquida e independência de financiamentos

7. Remuneração e vínculo regulares dos trabalhadores sócios e não-sócios

8. Investimento na formação de recursos humanos

9. Férias ou descanso semanal para os sócios-trabalhadores

Os itens avaliados dizem respeito ao grau de autonomia material (1 e 2), à abrangência e ao êxito da comercialização ( 3 e 4), a inversões em prol da consolidação dos EES (5 e 8), à geração de excedentes (6) e ao patamar de distribuição dos resultados para os sócios (7 e 9).

- Coeficiente de alto solidarismo:

1. Coletivização da produção ou do trabalho

2. Decisões coletivas tomadas pelo conjunto de sócios

3. Gestão de contas transparente e fiscalizada pelos sócios

4. Participação cotidiana na gestão do empreendimento

5. Matérias-primas ou insumos principais de origem solidária

6. Comercialização solidária e preocupação com os consumidores

7. Participação em movimentos sociais e em ações sociais ou comunitárias

8. Participação em redes políticas ou econômicas solidárias

9. Ações de preservação do ambiente natural

Os quesitos avaliados relacionam-se ao grau de cooperação produtiva (1), à participação e democracia na gestão $(2,3$ e 4), às práticas solidárias de comercialização (5 e 6), ao engajamento social e político (7 e 8) e à contribuição para o desenvolvimento sustentável (9).

Os indicadores de alto empreendedorismo foram atingidos em média por $8,7 \%$ dos EES. ${ }^{11}$ Quase a metade dos EES não preenche nenhum indicador e um terço atende apenas a um indicador. Somente $5 \%$ atendem a três indicadores ou mais. No tocante ao alto solidarismo, os percentuais de satisfação dos indicadores são superiores, alguns acima de $25 \%$ e na média geral $22,2 \%$, refletindo-se no desempenho global superior dos EES: apenas $15 \%$ não pontuam em nenhum indicador; $31,8 \%$ pontuam em 3 indicadores ou mais; $5,3 \%$, em 5 indicadores ou mais (contra apenas $0,4 \%$ no alto empreendedorismo). ${ }^{12}$

\footnotetext{
${ }^{11}$ Esses percentuais referem-se à totalidade dos EES e seriam maiores se desconsiderassem os casos em que certos quesitos embutidos nos indicadores são inaplicáveis. Tal correção não afetaria as conclusões gerais aqui apresentadas.

12 Cruzamentos complementares entre os coeficientes de alto e de baixo desempenho comprovaram a consistência do instrumento: por um lado, os perfis de baixo e de alto desempenho excluem-se; por outro lado, em apenas 15 casos a pontuação simultânea dos EES em ambos os coeficientes chega a 9, isto é, a $50 \%$ da pontuação teórica máxima.
} 
Assim concebidos, os indicadores de alto desempenho têm a faculdade de apontar os atuais pontos de estrangulamento dos EES. No quesito empreendedorismo, as fraquezas situam-se no investimento em formação de recursos humanos, na obtenção de crédito para investimento, na concessão de férias ou descanso semanal para os trabalhadores e na estrutura de comercialização. Deficiências relacionadas não tanto ao funcionamento diário dos EES, mas a debilidades estruturais que perduram, afetando o seu reconhecimento pelo mercado e reduzindo sua capacidade de gerar excedentes que garantam autonomia econômica, retribuições aos trabalhadores, coesão e qualificação do quadro de sócios. No quesito solidarismo, os pontos frágeis são a participação em redes, o comércio e o consumo solidários. Aqui, trata-se de limites nos relacionamentos externos, impostos pela fragilidade das iniciativas de articulação e pela inexistência de cadeias produtivas solidárias, capazes de estender-se e romper o isolamento dos empreendimentos, algo ainda distante da realidade.

Afora esses nós górdios, os percentuais de EES que atendem aos demais indicadores são mais altos, entre $9 \%$ e $44 \%$. Ademais, como vimos, poucos EES situam-se abaixo dos patamares mínimos. Deduz-se então que a maior parte dos empreendimentos apresenta um perfil de empreendedorismo e de solidarismo aquém de um alto desempenho. Eles não estão colados aos patamares mínimos, mas tampouco concentrados no topo. Sua maioria nem apresenta características sistematicamente negativas, contrárias ao empreendedorismo solidário, nem se destaca por propriedades altamente desenvolvidas. À luz do nosso instrumento de análise, eles estão acima do ponto crítico e abaixo do ponto ótimo: distribuem-se pelo gradiente existente entre esse dois níveis, com práticas variáveis, em geral limitadas, mas efetivas de economia solidária.

\section{Os compassos da nova racionalidade}

A hipótese de uma nova racionalidade implica ainda que as práticas determinadas por fins sociais e por fins econômicos evoluam complementarmente. Para verificá-lo, através do método empregado até aqui, deve-se analisar os coeficientes de forma integrada e examinar se as variações observadas nos indicadores de alto empreendedorismo e de alto solidarismo estão correlacionadas. Assim, podem-se avaliar as correlações entre as práticas e características de solidarismo interno e externo dos EES e aquelas de eficiência e viabilidade econômica.

A pontuação total dos EES nos dois coeficientes reflete globalmente as situações já evidenciadas em cada um deles. A grande maioria apresenta pontuação modesta e apenas $8 \%$ dos EES satisfazem mais de 5 indicadores. 
Entre os EES com escore entre 1 a 3 indicadores, não se pode afimar que a concomitância entre as pontuações no alto solidarismo e no alto empreendedorismo seja regra, pois um caso poder ocorrer sem o outro. Em contrapartida, os dados sugerem que o conjunto de EES obedece a uma relação positiva entre maior solidarismo e maior empreendedorismo: a cada grau de empreendedorismo corresponde um grau proporcionalmente maior de solidarismo. Os casos de desenvolvimento unilateral seriam minoritários. O fato converge com estudos qualitativos segundo os quais o desenvolvimento da dimensão empreendedora não inibe forçosamente a autogestão e o engajamento social dessas organizações, mas é suscetível de estimulá-los ou mesmo pressupô-los (Gaiger, 2006).

Podemos indagar se essa correspondência geral decorre de alguma situação específica, isto é, se alguns indicadores, num coeficiente, exercem uma força de indução sobre indicadores do outro coeficiente. $\mathrm{O}$ atendimento aos primeiros representaria uma condição favorável ao atendimento dos segundos, sinalizando então que a dimensão empreendedora e a dimensão solidária encontram-se ali fortemente integradas. As práticas correspondentes a tais indicadores funcionariam como nódulos de entrelaçamento entre solidarismo e empreendedorismo, cerne da racionalidade em exame.

Uma técnica estatística apropriada a essa questão é análise de correspondências, que consiste em mensurar as correlações simultâneas entre todos os indicadores, verificando quais tendem a andar juntos, a se repelirem ou a manterem-se neutros, sem relações significativas. Os resultados de sua aplicação ao nosso estudo mostram que as atrações mais importantes ocorrem sempre entre os indicadores da mesma dimensão: práticas ou características de alto solidarismo, por exemplo, relacionam-se mais fortemente entre si do que com as práticas ou características de empreendedorismo. ${ }^{13}$ Ainda assim, a análise mostra que certas práticas de empreendedorismo se fazem acompanhar de bons indicadores de solidarismo, evidenciando a presença de uma dinâmica ao mesmo tempo econômica, social e política: de um lado, no campo do fortalecimento econômico interno dos empreendimentos, através do desenvolvimento da capacidade de contração de crédito e de investimento, conjugado a seu fortalecimento externo via inserção em redes de comercialização solidária; de outro lado, no campo da observância dos direitos sociais do trabalho e de medidas de preservação ambiental, fatores de coesão interna e alinhados ao desenvolvimento sustentável.

${ }_{13}$ É possível que existam elos consideráveis vinculando os dois aspectos, porém não de forma genérica, para a maioria dos EES. Isto é compreensível, por conta da diversidade da economia solidária. 
Quando se considera a estrutura dos indicadores de cada coeficiente, os resultados são interessantes. As práticas de alto empreendedorismo aparecem divididas em dois blocos, evidenciando que os EES de maior pontuação apresentam matizes diferenciados. De um lado, aqueles que adquirem as condições econômicas e optam por manter um quadro regular de trabalhadores, concedendo-lhes direitos sociais e investindo na sua formação e qualificação. De outro lado, os EES que apresentam estratégias direcionadas à comercialização, acesso creditício ou recursos para investimentos, além de auto-suficiência econômica e financeira. Tais situações não são excludentes, mas constituem dois perfis relativamente independentes.

Os indicadores de alto solidarismo apresentam igualmente dois tipos de correlação mais fortes: em primeiro lugar, entre as práticas de participação e de transparência administrativa, vértices da gestão democrática. Em segundo lugar, entre a inserção em ações comunitárias ou movimentos sociais e os cuidados com a preservação ambiental, a denotarem envolvimento com os problemas da sociedade. Esses aspectos relacionam-se secundariamente a outras práticas mais específicas, como a comercialização solidária e a participação cotidiana dos sócios na gestão do empreendimento, aparecendo ainda, favoravelmente, situações de coletivização do trabalho ou da produção. Existiria assim uma correlação entre solidarismo interno e externo.

Ao estudar mais amiúde os indicadores, por meio de sua inclusão judiciosa em testes sucessivos de correspondências, discernem-se as vias de convergência que progressivamente se estabelecem entre as práticas em questão. A partir da conquista de um patamar de gestão democrática, os EES lançam-se no papel de atores sociais da economia solidária, mediante engajamento comunitário e práticas de articulação política e econômica ou, numa segunda via, investem prioritariamente em políticas de valorização do trabalho, mediante remuneração regular, benefícios sociais e formação dos recursos humanos. Esses caminhos mostram-se relativamente independentes dos avanços propriamente econômicos, como acesso a crédito, capacidade de investimento, facilidades de comercialização e penetração ampla no mercado. Ou seja, um alto desempenho econômico pode ser alcançado por EES situados em quaisquer das estratégias de desenvolvimento acima apontadas, de modo que as mesmas devem-se não a imposições da realidade econômica em si, mas a fatores singulares que afetam os diferentes EES em seu processo histórico. Pode-se dizer que representam uma questão política para os EES, de escolhas orientadas por sua identidade e por seu projeto. 


\section{Outra racionalidade faz diferença?}

No âmbito dessa análise geral dos dados, importa explorar uma derradeira linha de questionamento, atinente às características típicas dos EES com melhor desempenho empreendedor e solidário, do ponto de vista da gênese dos mesmos, do seu desenvolvimento posterior e dos seus resultados. Empreendimentos antigos, escolados por anos de dura concorrência no mercado, refluem em suas práticas solidárias ou as mantêm? O que sucede com os empreendimentos de grande porte, cujo elevado quadro de sócios acarreta empecilhos à democracia direta? À luz dos indicadores, aqueles EES de maior solidez econômica, com volumes de produção consideráveis, sacrificam os seus aspectos sociais e tendem a adotar uma lógica empreendedora convencional? As respostas a tais perguntas deixarão mais claro se a presença da nova racionalidade, mesmo sendo parcial e sujeita a contradições e reveses, é apenas um aspecto singularizante dessas iniciativas ou constitui um dos seus pilares estruturantes, exercendo um papel fundamental.

A tabela abaixo elucida um primeiro aspecto, relativo aos motivos principais da criação dos EES. ${ }^{14} \mathrm{~A}$ justificativa mais usualmente declarada, de busca de alternativa ao desemprego (31\%), ${ }^{15}$ refere-se aos EES cujo desempenho fica abaixo da média (última linha), o que respalda a idéia de que não bastam fatores externos de pressão negativa sobre os trabalhadores para que o resultado seja mais uma boa iniciativa de economia solidária (Gaiger, 2004c). Na mesma posição ficam os EES cuja finalidade inicial tinha um cunho pragmático (acesso a financiamentos e apoios) ou refletiam uma dinâmica ampla (desenvolvimento comunitário), talvez sem objetivos claros no campo econômico. Com índices acima da média, ganham destaque os EES formados com o objetivo deliberado de socializar a atividade econômica (desenvolver atividade onde todos são donos), cujo coeficiente de alto solidarismo é o mais elevado, e os casos de luta coletiva pela reconversão de empresas privadas em falência, nos quais o coeficiente de alto empreendedorismo é quase três vezes superior à média. Seja por uma opção refletida ou pela força imperiosa das circunstâncias, a motivação inicial faz diferença justamente quando comporta a dupla dimensão, social e econômica, do empreendimento a ser criado. Provavelmente por isso, entre os EES com maior pontuação, os coeficientes de empreendedorismo e de solidarismo tendem a evoluir lado a lado, como vimos antes.

\footnotetext{
${ }^{14}$ Como a pontuação da totalidade dos EES mapeados é baixa nos indicadores de alto empreendedorismo e solidarismo, não existem variações expressivas em números absolutos, sendo de considerar as diferenças relativas nas pontuações médias dos subconjuntos de EES delimitados pelos critérios em análise.

${ }^{15}$ A questão era de respostas múltiplas, contabilizando-se aqui o motivo declarado como principal.
} 
TABELA 1 - Desempenho médio dos EES segundo o motivo principal de sua criação

\begin{tabular}{|c|c|c|c|}
\hline $\begin{array}{l}\text { Motivo declarado de criação } \\
\text { do empreendimento }\end{array}$ & $\begin{array}{l}\text { Coeficiente de } \\
\text { alto empreende- } \\
\text { dorismo }\end{array}$ & $\begin{array}{l}\text { Coeficiente } \\
\text { de alto } \\
\text { solidarismo }\end{array}$ & $\begin{array}{l}\text { Coeficiente } \\
\text { integrado }\end{array}$ \\
\hline Uma alternativa ao desemprego & 0,7505 & 1,8750 & 2,6316 \\
\hline $\begin{array}{l}\text { Obter maiores ganhos em um em- } \\
\text { preendimento associativo }\end{array}$ & 0,8013 & 2,0039 & 2,8067 \\
\hline $\begin{array}{l}\text { Uma fonte complementar de renda } \\
\text { para os associados }\end{array}$ & 0,8057 & 2,0953 & 2,9073 \\
\hline $\begin{array}{l}\text { Desenvolver uma atividade onde to- } \\
\text { dos são donos }\end{array}$ & 0,8582 & 2,4166 & 3,2788 \\
\hline $\begin{array}{l}\text { Condição exigida para ter acesso a } \\
\text { financiamentos e outros apoios }\end{array}$ & 0,5623 & 1,9692 & 2,5350 \\
\hline $\begin{array}{l}\text { Recuperação por trabalhadores de } \\
\text { empresa em falência }\end{array}$ & 2,1111 & 2,3857 & 4,5143 \\
\hline $\begin{array}{l}\text { Motivação social, filantrópica ou re- } \\
\text { ligiosa }\end{array}$ & 0,7974 & 1,9934 & 2,7881 \\
\hline $\begin{array}{l}\text { Desenvolvimento comunitário de ca- } \\
\text { pacidades e potencialidades }\end{array}$ & 0,7356 & 1,7864 & 2,5194 \\
\hline $\begin{array}{l}\text { Alternativa organizativa e de quali- } \\
\text { ficação }\end{array}$ & 0,7271 & 2,1945 & 2,9291 \\
\hline Médias gerais dos EES & 0,7531 & 2,0024 & 2,7595 \\
\hline
\end{tabular}

Quando submetidos à prova do tempo, os EES que sobreviveram até o Mapeamento não parecem descaracterizar-se: aqueles cuja fundação ocorreu antes de 1980 exibem o melhor desempenho global, com um bom índice de alto solidarismo e o maior índice de alto empreendedorismo. No outro extremo, os EES fundados há menos de uma década, entre eles os mais recentes e compreensivelmente mais frágeis, apresentam os níveis de alto empreendedorismo mais modestos, mas também índices de alto solidarismo tendencialmente abaixo da média. O melhor perfil nesse quesito corresponde aos EES ao redor de 15 anos de funcionamento. Por razões melhor esclarecidas adiante, o tempo parece fazer bem aos empreendimentos: preserva aqueles dotados de estratégias eficientes de sustentação econômica e, 
ao mesmo tempo, seleciona as iniciativas com melhores práticas de participação e autogestão. Nos detalhes, nota-se que os EES submetidos à redução no número de sócios também apresentam um desempenho menor que os demais, depreendendo-se daí que os eventos de adesão e de evasão de trabalhadores não estão descolados das possibilidades que possuem estas organizações de conciliarem suas exigências econômicas e sociais.

A longevidade dos EES até certo ponto está ligada à sua forma de organização. Na maior parte dos casos, eles nascem como grupos informais e muitas vezes, quando mais estruturados, registram-se posteriormente como associações ou cooperativas. Assim, as cooperativas são mais antigas que as associações ou os grupos informais e correspondem geralmente a iniciativas com um potencial mais consolidado. Tendo-se em vista as exigências contidas na transição para o formato cooperativo, quanto a regras formais de gestão e aos demais requerimentos institucionais, entende-se por que as cooperativas apresentam índices bastante superiores aos demais EES, enquanto os grupos informais ficam em último lugar nesse comparativo, com deficiências visíveis no campo do solidarismo.

Além disso, as cooperativas em geral são empreendimentos maiores. Desse ponto de vista, os dados não deixam dúvidas: quanto maior o quadro de sócios, melhor o desempenho dos EES, com ênfase para a faixa superior a 50 membros, em ambos os coeficientes. As deficiências dos pequenos grupos informais aparecem agora por outro prisma: segundo os indicadores, EES com até 10 integrantes são em média menos solidários que os de médio e grande porte. Não obstante as dificuldades inerentes à condução de organizações autogestionárias de porte, a economia solidária não se revela aqui uma alternativa típica ou cativa de pequenos empreendimentos, aos quais não daria chances de crescer. Pelo contrário, os EES que admitiram novos sócios no período anterior ao Mapeamento exibem índices de desempenho superiores àqueles com quadro estável ou com perda de membros.

Os dados sobre as diferenças causadas pelo predomínio de homens ou de mulheres no quadro social são dignos de interesse para análises específicas na perspectiva de gênero. Entre os EES de maior porte, aqueles com elevado número de homens sócios apresentam um desempenho global superior, em particular no coeficiente de empreendedorismo. Essa tendência contudo é mais acentuada entre os EES maiores com elevado número de mulheres sócias. Ademais, nesse caso há um equilíbrio entre os dois coeficientes, o que dá guarida a muitos estudos atuais sobre a presença das mulheres na economia solidária e suas consequências positivas para as mulheres e para a economia (Guérin, 2003). 
A vantagem dos EES com maior estrutura estende-se ao volume das atividades econômicas. Os índices de desempenho empreendedor e solidário são nitidamente superiores nos EES que se destacam por cifras econômicas elevadas, nos quesitos de produção, crédito, investimento e remuneração dos sócios trabalhadores. Por seu turno, os EES com valor da produção não declarado, sem acesso a crédito, sem investimentos e com faixas de remuneração reduzidas apresentam os menores quocientes de alto empreendedorismo e alto solidarismo. Salvo exceções, o índice de alto solidarismo sempre acompanha o incremento da atividade econômica, constatação fundamental para nossa análise. O escore dos EES no coeficiente integrado de empreendedorismo e solidarismo cresce, pela ordem, com os níveis de faturamento, investimento, crédito e remuneração. Reaparece o vínculo positivo entre participação e rendimento econômico (Jones, 1978).

É ainda pertinente dimensionar o impacto das ações externas de apoio aos empreendimentos, por ser essa uma característica marcante da economia solidária. Um primeiro dado revela que os EES declarantes de apoios recebidos, sob forma de assessoria, assistência ou capacitação, apresentam índices superiores aos não declarantes, exceto os casos de apoio de órgãos governamentais. Assim, os apoios externos, se nem sempre muito ajudam, tampouco mostram-se inúteis ou prejudiciais. Percebe-se que as formas a princípio mais convencionais e padronizadas de apoio, ou voltadas a um objetivo momentâneo, não surtem maiores efeitos. Já as ações continuadas e as assessorias que incidem sobre gargalos conhecidos dos empreendimentos, como os aspectos jurídicos ou ligados à comercialização, produzem os melhores resultados. Quanto à origem dos apoios, o diferencial positivo é causado, de maior a menor, por cooperativas de técnicos, instâncias do movimento sindical, universidades e entidades civis. O conhecimento técnico parece assim ter vigor apenas quando associado à cultura cooperativa e ao ambiente social e político da economia solidária. ${ }^{16}$

\section{Considerações finais}

Da análise anterior conclui-se que os fatores a impulsionar os EES não são circunstanciais ou aleatórios, pois se ligam à trajetória dessas experiências, não à contra-corrente de suas práticas empreendedoras e solidárias, mas justamente por serem as mesmas exercidas. Em outros termos, tais práticas, cujas conexões sustentam a tese de uma racionalidade peculiar dessas orga-

\footnotetext{
${ }_{16}$ Dados complementares indicam ainda uma vantagem dos EES que resolvem internalizar os conhecimentos técnicos necessários, com a incorporação de profissionais especializados ao seu quadro de funcionários.
} 
nizações, são-lhes estruturantes. O efeito apreciável provocado por situações à primeira vista sem maiores conseqüências, como o predomínio das mulheres no quadro social, avaliza a idéia de que se conduzir segundo as pautas de outra economia faz uma considerável diferença. Já os reflexos positivos da maior parte dos apoios externos recebidos pelos EES, expressando o interesse e o amparo da sociedade para com a economia solidária, justificam que ela seja entendida como um campo próprio, a merecer novas regulações em prol do ato associativo.

Uma compreensão mais profunda das atuais iniciativas de economia solidária, a partir das aquisições iniciais proporcionadas por esse estudo da racionalidade dos empreendimentos em geral, requer adentrar os diversos segmentos da economia solidária isto é, os subconjuntos de experiências que partilham uma história comum e possuem uma morfologia similar, a exemplo das associações de produtores familiares, das cooperativas industriais ou das unidades coletivas de reciclagem. Cada segmento pode ter seu desempenho solidário e empreendedor apurado e comparado com os índices gerais, o que destacaria suas singularidades e as elucidaria melhor. Outra possibilidade, de acordo com o método aqui empregado, consistiria em comparar os EES que apresentam um perfil solidário e empreendedor semelhante, a despeito de sua heterogeneidade morfológica, o que permitiria cruzar tipologias de desempenho qualitativo dos empreendimentos com tipologias de conteúdo histórico-social.

As vias de evolução da economia solidária em nada se parecem a um caminho conhecido e seguro. A razão pragmática com certeza não serviria para escrutinar a realidade presente e admitir, nas possibilidades nela contidas, desenlaces emancipatórios. No entanto, "muito provavelmente será a capacidade de ir inscrevendo o futuro nas vivências do presente que mais efectivamente nos pode aproximar dele" (Namorado, 2005: 19). Para os trabalhadores da economia solidária, os seus empreendimentos representam desafios incomuns, mas não utópicos, pois são hoje a realidade que experimentam e vivem com esperança (Santos, 1999), convertendo essa práxis em seu regime de verdade. Nossos esforços de compreensão não deveriam perder de vista que o sentido da economia solidária, em sua instância primordial, depende do que representar para a vida dos trabalhadores, diante das demais alternativas de trabalho, renda e inserção social a seu dispor, considerando-se suas aspirações a uma vida com valor e dignidade. Reside, ademais, nos novos protagonismos que essas iniciativas ensejam, na esfera econômica e nos espaços públicos, em cujos embates forjam-se repetidamente, desde as lutas democráticas dos anos 80 no Brasil, os atores populares da cidadania. 


\section{Referências bibliográficas}

Abramovay, Ricardo (org.) (2004), Laços financeiros na luta contra a pobreza. São Paulo: Annablume.

Cattani, Antônio (org.) (2004), La otra economía. Buenos Aires: Altamira (trad. Lucimeire Leite).

Coraggio, José (1999), Política social y economía del trabajo. Buenos Aires/Madrid: Miño y Dávila Editores.

Coraggio, José (org.) (2007), La economía social desde la periferia. Contribuciones latinoamericanas. Buenos Aires: UNGS-Altamira.

Defourny, Jacques (1988), "Coopératives de production et entreprises autogérées: une synthèse du débat sur les effets économiques de la participation”, Mondes en Développement, 61(16), 139-53.

França Filho, Genauto et al. (orgs.) (2006), Ação pública e economia solidária. Uma perspectiva internacional. Porto Alegre: UFRGS.

Gaiger, Luiz (2004a), "Eficiencia sistémica", in Antônio Cattani (org.), La otra economía. Buenos Aires: Altamira, 213-220.

Gaiger, Luiz (2004b), "Emprendimientos económicos solidários", in Antônio Cattani (org.), La otra economía. Buenos Aires: Altamira, 229-241.

Gaiger, Luiz (org.) (2004c), Sentidos e experiências da economia solidária no Brasil. Porto Alegre: UFRGS.

Gaiger, Luiz (2006), "A racionalidade dos formatos produtivos autogestionários", Revista Sociedade e Estado, 21(2), 513-44.

Gaiger, Luiz (2007), "Nouvelles formes de production non capitaliste au Brésil", Revue Tiers Monde, 190, 309-324.

Guérin, Isabelle (2003), Femmes et économie solidaire. Paris: La Découverte.

Jones, Derek (1978), "Les coopératives de producteurs dans les économies occidentales industrialisées: un aperçu général", Annales de l'économie publique, sociale et coopérative, 66(2), 109-124.

Laville, Jean-Louis (org.) (2004), Economia social y solidaria. Una visión europea. Buenos Aires: Altamira (trad. Mirta Vuotto).

Lévesque, Benoît et al. (orgs.) (2001), La nouvelle sociologie économique. Paris: Desclée de Brouwer.

Mendell, Marguerite (2003), "La aparición de movimientos sociales internacionales y la economía social y solidaria", Économie et Solidarités - Revue du CIRIEC/Canadá [n. ${ }^{\circ}$ especial], 19-29.

Namorado, Rui (2005), "Cooperativismo - um horizonte possível”, Oficina do CES, 229.

Novaes, Henrique (2005), "Quando os patrões destroem máquinas. O debate em torno das forças produtivas em fábricas recuperadas argentinas e uruguaias", Revista Ciências Sociais Unisinos, (41)2, 100-110. 
Razeto, Luis (1993), "Economia de solidariedade e organização popular", in Moacir Gadotti; Francisco Gutiérrez (orgs.), Educação comunitária e economia popular. São Paulo: Cortez, 34-58.

Santos, Boaventura de Sousa (1999), "Porque é tão difícil construir uma teoria crítica?", Revista Crítica de Ciências Sociais, 54, 197-215.

Santos, Boaventura de Sousa (org.) (2002), Produzir para viver. Os caminhos da produção não capitalista. Rio de Janeiro: Civilização Brasileira.

Singer, Paul (1999), Uma utopia militante. Petrópolis: Vozes. 